\title{
A Comparison of Navigation Model between UWE and WebML: Homepage Development Case Study
}

\author{
Karzan Wakil, Dayang N. A. Jawawi, and Amirhossein Safi
}

\begin{abstract}
Web Engineering is a systematic approach for the development of web applications. In this area navigation model is defined as an important model in all the hypermedia and web engineering methods. Also homepage is one of the most important pages on the websites, because it is considered to be the key element that demonstrates the quality of websites. The web engineering methods still have weaknesses that are difficult for designers to design homepage's content perfectly. In this paper we compare navigation model between UML-Based Web Engineering (UWE) and Web Modeling Language (WebML). The purpose of this paper is to find a quality in these methods for the homepage's development, through designing navigation model in UWE and WebML, and comparing the elements of the navigation model. The result of this paper helps the designers to develop the homepages in order to solve of the weakness's navigation model.
\end{abstract}

Index Terms-Web engineering, navigation model, homepage, UWE, WebML.

\section{INTRODUCTION}

Web engineering is the application of systematic, disciplined and quantifiable approaches to the cost-effective development and evolution of high-quality solutions in the web-based applications. In web engineering there are lots of methods to develop the web applications like; UWE, $\mathrm{OOH}$, WebML, OOWS, and OOHDM [1]. Though most of the Web Engineering methods define their own notation for creating models like presentation model and navigation model, Koch and Kraus stated that; in many cases it is just another notation for the same concepts, meaning they must be based on a common metamodel for the Web application area [2].

In most of the cases another notation can be used for the same concept, or furthermore, common metamodel which the basis must be used for web application area.

One of the possible debatable concepts used in the web community is the concept of navigation. In this paper we describe the inclusion process design of the navigation model for two well known methods that called UWE and WebML.

Both UWE and WebML have the same concept features in metamodels; but with dissimilar process in the web applications development of that will be distinguished in this paper.

UWE is a software engineering approach for the web applications, whose objective is to cover the entire life-cycle

Manuscript received February 27, 2014; revised May 18, 2014

Karzan Wakil is with Fine Arts Institute in Sulaimaniyah, Iraq (e-mail: karzanwakil@gmail.com).

Dayang N. A. Jawawi and Amirhossein Safi are with the Software Engineering Department, Faculty of Computing, Universiti Teknologi, Malaysia (e-mail: dayang@utm.my, samirhossein2@utm.my). for the development of web application, processing an object oriented and iterative approach depended on the Unified Software Development Process (USDP) [3]. The primary concentration of the UWE method is the design that systematically used by a semi automatic generation of web applications [4].

WebML [5] came in a picture in 1998 by an Italian Politecnico di Milano research group. UML is a visual modelling language of construction, specification and documentation of systems which are used in web application domains and execution platform. It is also widely adopted by both academia and industry as a regular language for relating software systems[6].

The web engineering methods provide a number of advantages compared to ad hoc development. The web engineering methods are directed through the process of software creation, and provide a whole documentation, take into consideration the need of users, and which can be a certain quality. All these problems of web engineering methods help to decrease the costs of development, that for sure is an essential aim in the development of software[7].

In other side homepage is one of the most important pages on the website, because clearly communicates the site's purpose, show all major options available on the page and the key that showing the quality of websites. Solving the usability of homepage helps it to be elegance, clear, easy user interface and easy for understanding [8], [9].

Through comparing navigation model between UWE and WebML this paper aims at finding the weakness and the strengths of the both methods.

The paper is organized as follows: the Section II explains the background work of the UWE and WebML especially navigation model. In the Section III we selected the case study and analyzed it. The Section IV demonstrates the designing navigation model for the case study by UWE and WebML. In the Section V we will make a comparison for navigation model between UWE and WebML based on the case study. In the Section VI presents some concluding remarks and points to future works.

\section{BACKGROUND}

In the past few years, some Web Engineering methods have suggested an operation to develop Web Applications. The generic method has proposed five steps that one of them is a description of navigation model which presents navigation between the application nodes [10].

In the web engineering community many researchers have found metamodeling and UML extensions in describing web models [11]-[16]. 
The notations that were used for designing "lightweight" UML-profile are explained in the previous works, e.g. [2]. A UML-profile is a UML after extension, it depends on the extension process that described by the UML side by side with the characteristics of using a standard notation. The UWE profile consists of "stereotypes and tagged values" that described for the modeling aspects necessary to model the various elements of web applications, like presentation, navigation, and adaptation aspects. Fig. 1 shows the package of the navigation model in UWE [2].

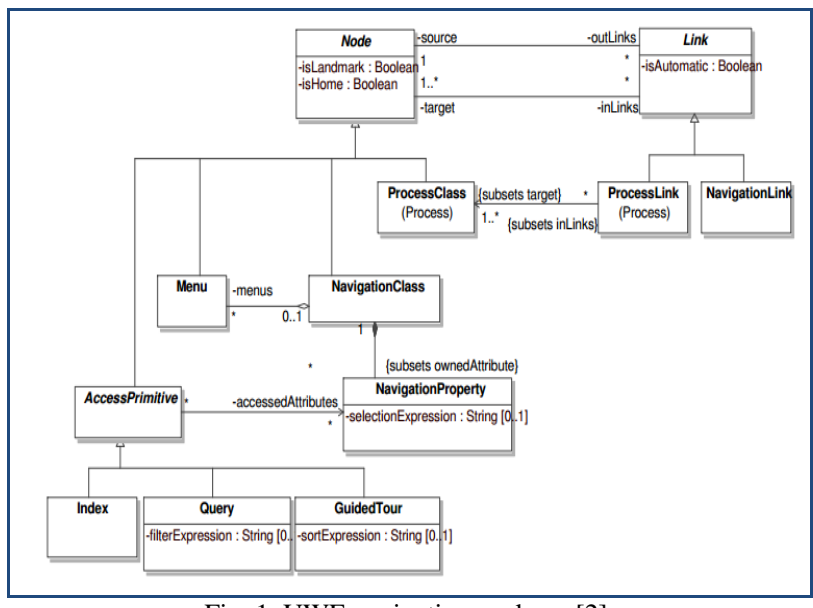

Fig. 1. UWE navigation package [2].

Navigation model is created from navigation classes, a set of guided tours, indexes, queries and links. Also the navigation classes and links are parts of conceptual classes. At the same time, the users are modeled through user properties, associations, and also the user plays an important role in the properties of the conceptual classes. Currently, an extension of the CASE-tool ArgoUML is being applied to support the creation of these UWE design models [17].

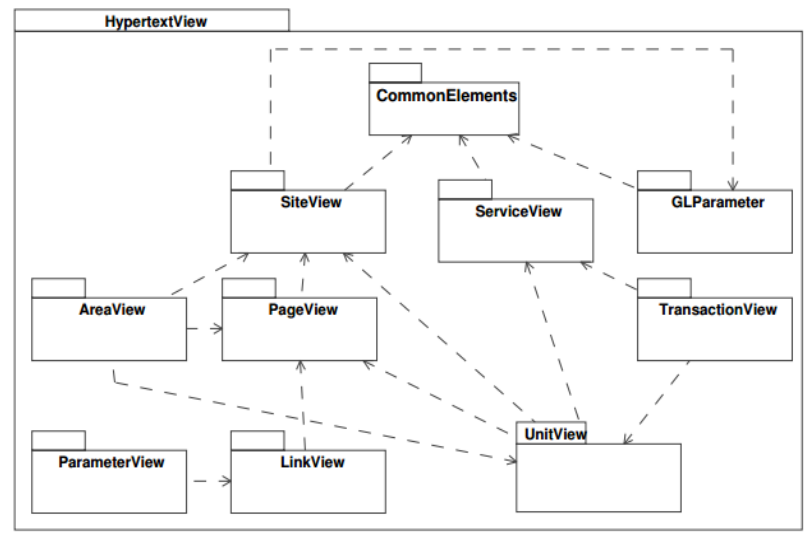

Fig. 2. Package structure of the hypertext WebML metamodel [18].

Conallen [12] in his work uses navigation with the Web Application Extensions (WAE) and the standard UML diagrams comprise the regular web artifacts (client pages, server pages, frames, and form). The key advantage of WAE proposal lies in it is easiness that allows Web Interface's design artifacts, at the same time it allows driving the application like interface. In the other side, this same easiness and being simple is an evidence of lacking of elements for tool independent requirements, representing technology, and modeling navigation. Finally, WAE is a low level suggestion for observing complexity in a high level of abstraction from the presentation and navigation viewpoints.

To solve these problems and restrictions, Gomez \& Cachero suggested in [14], some new views that extend UML diagram to provide the web interface model. Design by a UML follows the use case, a business class diagram, the navigation and presentation models, which are described by using a mixture of UML and proprietary primitives, in the Fig. 2 shows the package structure of the hypertext WebML metamodel.

The main goal is to present that navigation is an important aspect widely studied by a lot of researchers, such as comparison between requirements of the methods in [19], comparison business process development in [20], ccomparison between UWE, WebML and $\mathrm{OOH}$ in [21], Requirements Engineering In current web engineering methodologies [19], and comparison study describe advantages and disadvantages of some selected methods [22].

The previous works showed weaknesses and strengths of the web engineering methods through the comparison between them, however some of the researchers tried to improve web engineering methods and metamodels, but still it is not perfect for the web application development. So the web engineering methods until now need it to show the capability through the comparison, for evaluation and improvement of web engineering methods.

\section{CASE Study And AnAlysis}

In this section we select a case study, to design the navigation model for UWE and WebML, through these navigation models we can make a comparison between the two methods. We focus on homepage because it is one of the most important pages on the websites, and the key to showing the quality of websites.

There are many classifications for the typology of web pages and homepages. Jackson,1999, showed four ways for categorizing of web pages according to the organizer identity, number of pages, organizer's goal, which based on the measure and web pages [23]. Also Alistair Kennedy and Michael Shepherd, 2005, classified homepages for three categories which are: personal homepage, corporate homepage and organization homepage [24]. We choose a case study in each category that shown in Table I.

TABLE I: CATEGORIES OF HOMEPAGE WITH CASE STUDY

\begin{tabular}{|l|l|}
\hline \multicolumn{1}{|c|}{ Category } & \multicolumn{1}{c|}{ Case study } \\
\hline organization homepage & UTM homepage [25] \\
\hline corporate homepage & Apple homepage [26] \\
\hline personal homepage & Maher Zain homepage [27] \\
\hline
\end{tabular}

The UTM homepage has all of the modules design for homepages compare with Apple homepage and Maher Zain homepage, for example UTM homepage has menu, picture, contact us and etc. also used in Apple and Maher Zain's homepage.

Therefore in this paper in order to compare navigation model between UWE and WebML, we utilize the University Technology Malaysia's (UTM) homepage as a case study, because it is a completed homepage compare the other case studies, and it has different contents such as News, Search, 
Switch Languages, Information and etc. Also, it has different types such as Image and Text. Moreover, this homepage has different modules like Flash news, Frame and Menu that linked to some application like Chat and Feedback. Briefly, UTM homepage has all models that corporate and personal homepage used, Fig. 3 shows the UTM homepage, this picture was taken on the 30th October 2012 by using Fireshot software for Google Chrome browser.

TABLE II: CLASSIFICATION TYPE OF MODULES DESIGN OF THE UTM HOMEPAGE

\begin{tabular}{|c|c|c|c|}
\hline No. & Homepage's content & $\begin{array}{l}\text { Type of the } \\
\text { Modules Design }\end{array}$ & $\begin{array}{l}\text { Name of } \\
\text { Class }\end{array}$ \\
\hline 1 & Logo & Image & Image \\
\hline 2 & Head menu-Accessibility & Menu & Information \\
\hline 3 & Head menu-My UTM & Menu & Information \\
\hline 4 & Languages-English & Menu & Languages \\
\hline 5 & Languages-Malay & Menu & Languages \\
\hline 6 & Search & Search & Service \\
\hline 7 & Top Menu 1-About Us & Main menu & Information \\
\hline 8 & Top Menu 1-Admission & Main menu & Application \\
\hline 9 & About Us-introduction & Sub menu & Information \\
\hline 10 & About Us-facts \& history & Sub menu & Information \\
\hline 11 & Top Menu 2-Staff & Menu & Information \\
\hline 12 & Top Menu 2-Alumni & Menu & Information \\
\hline 13 & Flash News & Flash New & News \\
\hline 14 & Begin Virtual Tour & Image & Image \\
\hline 15 & Visitor's Counter & Counter & Service \\
\hline 16 & Where we are & Menu & Information \\
\hline 17 & News \& Announcement & Multi data & News \\
\hline 18 & Events@UTM & Multi data & News \\
\hline 19 & Find Us on-face book & Multi data & Connection \\
\hline 20 & Find Us on- twitter & Multi data & Connection \\
\hline 21 & Marquee Link & Marquee & Information \\
\hline 22 & Online service & Custom Model & Service \\
\hline 23 & Course Finder & Custom Model & Service \\
\hline 24 & Frame & Frame & Information \\
\hline 25 & Faculties and Schools & Custom model & Information \\
\hline 26 & Media & Custom model & information \\
\hline 27 & Campus & Image & Image \\
\hline 28 & $\begin{array}{l}\text { About Us-Vision \& } \\
\text { Mission }\end{array}$ & Menu & information \\
\hline 29 & Map and Direction & Image & Image \\
\hline 30 & Partners -KPT & Custom Model & Partners \\
\hline 31 & Partners -Msc & Custom Model & Partners \\
\hline 32 & Text & Custom mode & Information \\
\hline 33 & $\begin{array}{l}\text { Footer Menu-Agency } \\
\text { Policy }\end{array}$ & Menu & Information \\
\hline 34 & Footer Toolbar-Chat & Application & Application \\
\hline 35 & Feed Back & Application & Connection \\
\hline
\end{tabular}

The content of the UTM homepage consists of various kinds of module design. In this paper, we have chosen few of them, and grouped them for designing navigation models and presented them by methods as highlighted in Table II. Table II shows a sample of the type of module design, types of contents and classes for the UTM homepage content.

The UTM homepage used most of the modules for design. We selected and grouped as showed in Table II. The groups represented as one type of a model and supported by one notation in web engineering models elements. Thus, this helps the designers to find the elements of web engineering methods to represent the UTM homepage. In the next section we will design the navigation model by UWE and WebML methods.

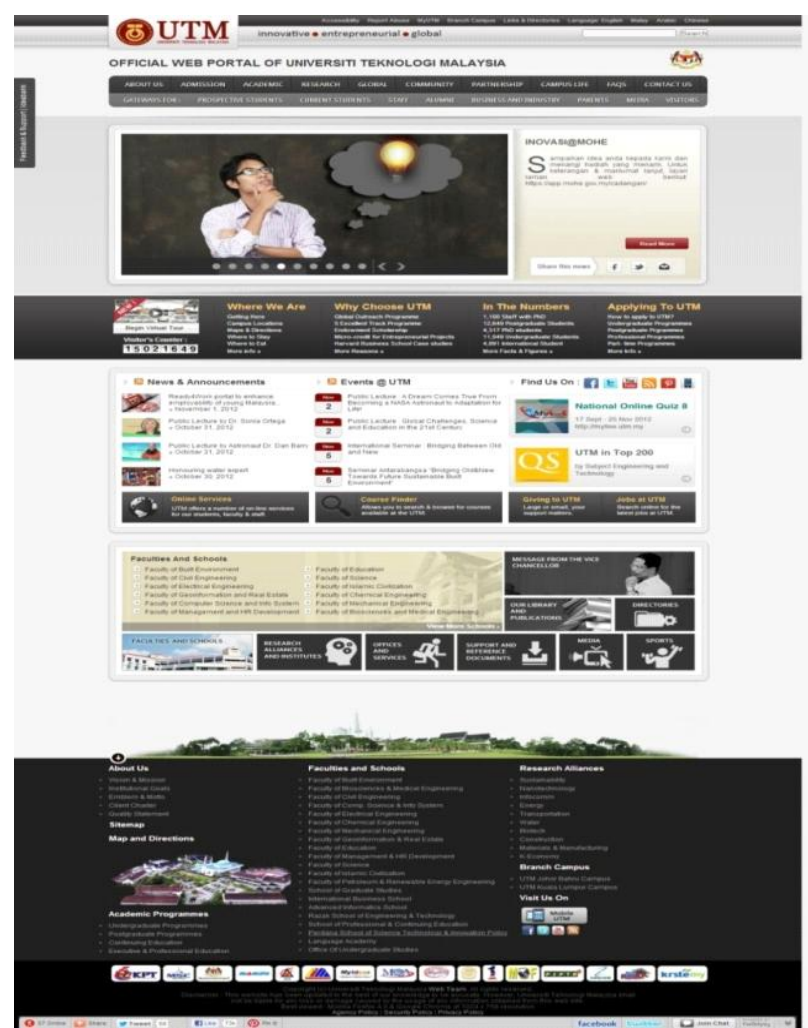

Fig. 3. UTM homepage.

\section{Design Case Study by Web Engineering Methods}

In this section we will implement the designing of a navigation model for the Case Study by two methods UWE and WebML.

\section{A. Designs by UWE}

For the design navigation model by the UWE method, we use the ArgoUWE tool. The following explains the design process of the navigation model.

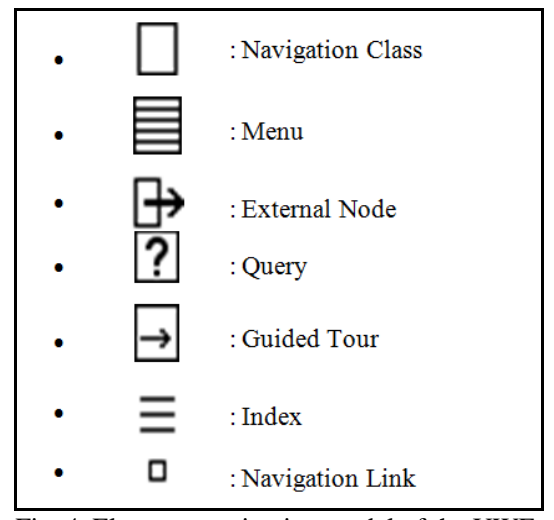

Fig. 4. Elements navigation model of the UWE.

UWE describes an iterative UML process for web applications that include the following steps: requirements, analysis, conceptual design, navigation design, presentation design and the process design that produces the number of artifacts are: a use case model, a conceptual model, a navigation model, and a presentation model [28]. In this paper we draw only navigation model for UTM homepage.

ArgoUWE tool is built for ArgoUML as a conservative addition of a plugin. Casteslyn in 2009, begins innovative forms of diagrams to represent the latest UWE particular model [29]. 
The navigation structure of a web application is designed depending on the content modeling and the requirement analysis. The hypertext structure's navigable nodes are classes of navigation and direct connection among navigation classes, which are depicted by navigation links. Menus manage the optional navigation paths in order to obtain various examples of a navigation class (guided tour or index), and item selection (query) a useful item is a primitive way of accessing. The elements that are used to design the navigation model in [17], [30], as shown in Fig. 4.

For drawing the navigation model, conceptual model is needed which was provided by ArgoUWE, and when the "Navigation Diagram: is drawn from the menu "Create Diagram" button, ArgoUWE creates navigation classes, and associations for every "navigation relevant". Some links can be added by the modeler following the creation of the navigation diagram automatically. As one of the buttons, automatic creation of indexes, menus, and queries are done by ArgoUWE.

At any time the diversity on the target end is more than one, the index is added between two classes of navigation that are connected via an organization. All the classes that have more than one outgoing association can obtain the Menus. Also all classes that related to queries can present by query. Fig. 5 shows the navigation model for the UTM homepage after adding enhancement elements (menu, index and query) by ArgoUWE tool.

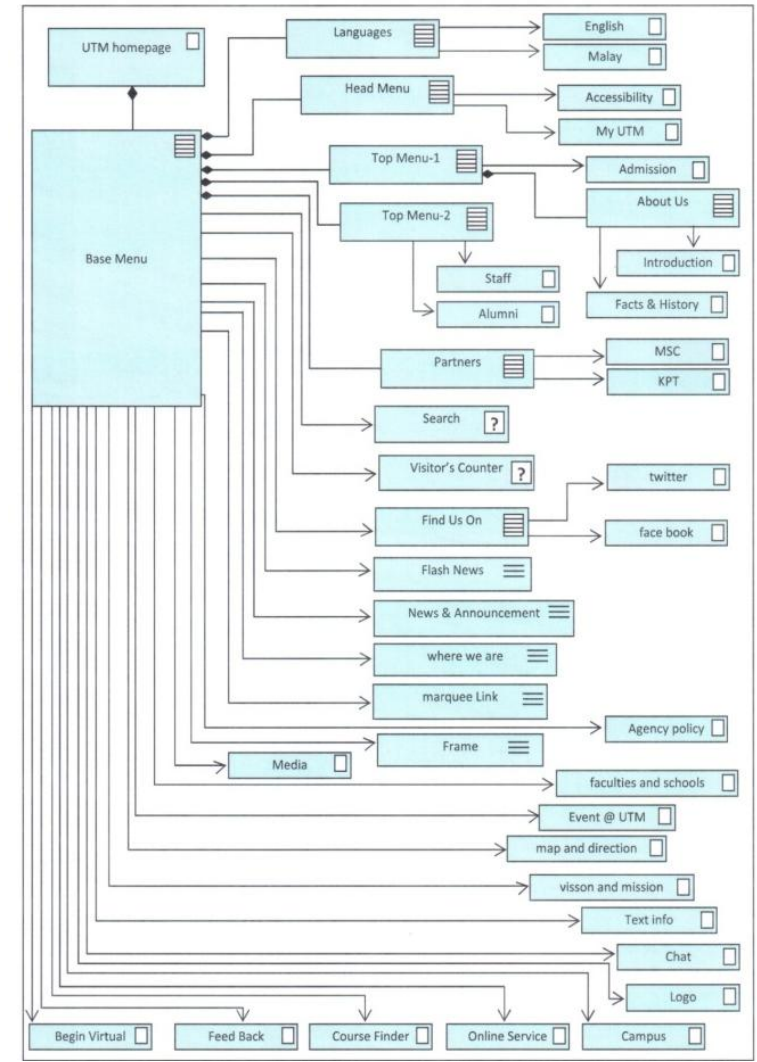

Fig. 5. UWE navigation model for the UTM homepage.

We designed the UWE Navigation model for the UTM homepage by using the current elements in UWE navigation model and ArgoUWE as shown in Fig. 4. In these diagrams we found the following points:

- Top Menu-1: we use another class (menu) for representing it.
- Flash News: we use another class (index) for representing it.

- Marquee Link: we use another class (index) for representing it.

- Where we are: we use another class (index) for representing it.

- News and announcement: we use another class (index) for representing it.

- Frame: we use another class (index) for representing it.

- Chat: we use another class (navigation class) for representing it.

However it seems the UWE navigation is a good diagram, but actually this diagram not perfect because we used another class instead of the special class, for example we use menu class for Topmenu-1, index for Flash news, and et al. There for we can conclude that UWE navigation model cannot support homepage content perfectly.

\section{B. Designs by WebML}

WebML is described as a graphical or visual language for clarifying the content component of a web application and the presentation of such content in a hypertext model [5].

Hypertext modeling clearly describes the composition and navigation of the website. Therefore the website pages are the information containers that the reader practically receives.

Fig. 6 shows the elements of WebML when is used to design hypertext diagram [31].

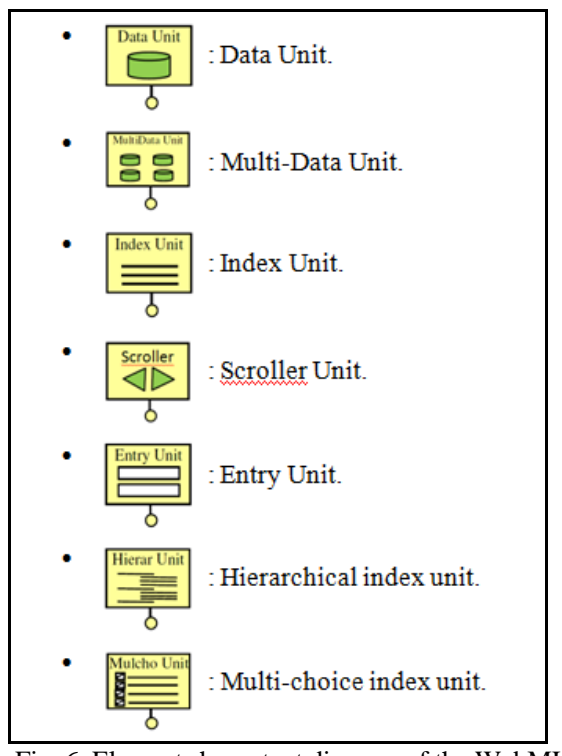

Fig. 6. Elements hypertext diagram of the WebML.

The Page comes as result of connection between the units, each Page consists of a set of units (shown as solid rectangles with different icons) to be displayed together in the site [31].

The process of designing WebML metamodels are a conceptual model, hypertext model and presentation model, in this paper we show only hypertext based on UTM homepage. The Fig. 7 shows WebML hypertext model for the UTM homepage.

We designed WebML hypertext model for the UTM homepage by using the current elements in WebML hypertext model and WebRatio as shown in Fig. 5. In the hypertext model diagram as showed in Fig. 5, showed the UTM homepage with the good support, because the WebML 
is a graphical language which also has more elements for representing homepage contents. However in a few cases it does not fully support such as Flash news, Marquee Frame and Application icon, but it is a strong method for the homepages development.

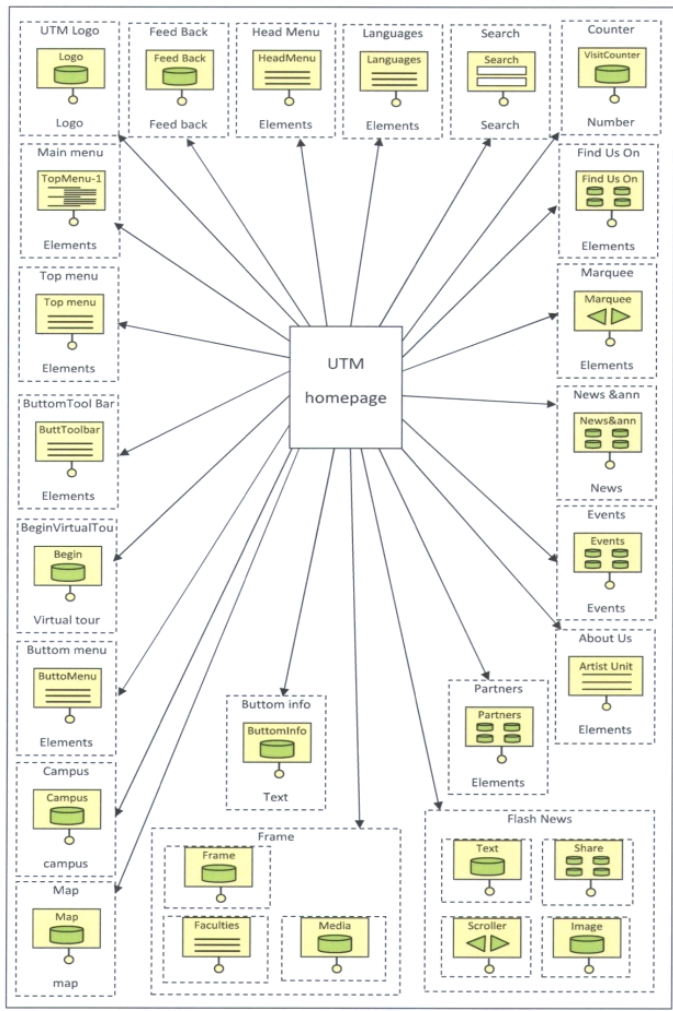

Fig. 7. WebML hypertext model for the UTM homepage.

\section{COMPARISON AND DISCUSSION}

After designing navigation model for the UTM homepage by UWE and WebML, we make a comparison between them. Table II shows a comparison between them to highlight the power of these methods over the development of the UTM homepage.

TABLE III: COMPARISON NAVIGATION MODEL BETWEEN UWE AND WEBML

\begin{tabular}{|c|c|c|}
\hline \multirow{2}{*}{$\begin{array}{l}\text { Types of Model Design } \\
\text { in Homepage }\end{array}$} & \multicolumn{2}{|c|}{ Navigation Model } \\
\hline & UWE & WebML \\
\hline \multicolumn{3}{|l|}{ Image } \\
\hline \multicolumn{3}{|l|}{ Text } \\
\hline \multicolumn{3}{|l|}{ Search } \\
\hline \multicolumn{3}{|l|}{ Main menu } \\
\hline \multicolumn{3}{|l|}{ Menu } \\
\hline \multicolumn{3}{|l|}{ Flash News } \\
\hline \multicolumn{3}{|l|}{ Counter } \\
\hline \multicolumn{3}{|l|}{ Multi Data } \\
\hline \multicolumn{3}{|l|}{ Marquee } \\
\hline \multicolumn{3}{|l|}{ Frame } \\
\hline \multicolumn{3}{|l|}{ Custom Model } \\
\hline \multicolumn{3}{|l|}{ Application } \\
\hline Not support & \multicolumn{2}{|c|}{ Not support } \\
\hline Partially support & \multicolumn{2}{|c|}{ Using another class } \\
\hline Half support & \multicolumn{2}{|c|}{ Seems to support but it is weak } \\
\hline Good support & \multicolumn{2}{|c|}{ Support but not perfect } \\
\hline Fully support & \multicolumn{2}{|c|}{ Fully support } \\
\hline
\end{tabular}

Table III, shows the design result of the navigation model in UWE and WebML. UWE cannot fully support all contents of the homepage, but WebML is better than UWE because WebML is a graphical language which has more elements for representing homepage contents.

As the result of this comparison we can conclude that both methods can represent Image, Text, Search, Menu, Counter and Custom Model. But WebML is weak to support Flash News, Marquee, Frame, and cannot support Application icons. UWE also cannot support main Menu, Flash News, Multi Data, Marquee, Frame and Application icons. According to this comparison WebML is better than UWE for developing homepages.

The elements of WebML which are; Multi-Data, Units, Hierarchical, index unit, Multi-choice, and Pages are elements that UWE cannot support it.

However, UWE is a standard method, and WebML is graphical method but both of them cannot fully support homepage contents because the number of elements of the navigation model is less than the types of the modules of homepages. We can improve the UWE navigation model and WebML navigation model to fully support the homepage contents .The UWE provides a UML profile; and WebML which based on UML. We can use the UML mechanism [32] to define new elements according to this method as showed Fig. 8 .

This demonstrated that the added features in the metamodels lead to more usability in concluding website. Extension mechanism helps the researchers to improve the web engineering methods for the web applications development and increase the usability of methods. In the following we present the steps of defining new elements from a mechanism that prepared by [32] as shown in Fig. 8 .

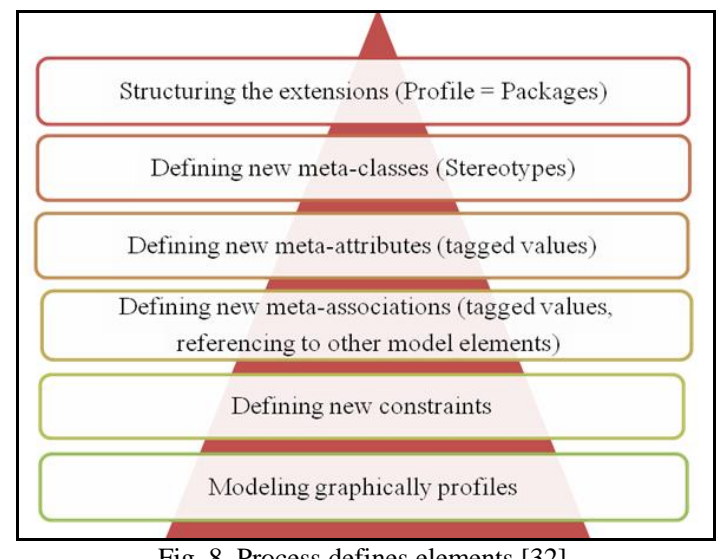

Fig. 8. Process defines elements [32]

For defining new elements we need the above steps as showed in Fig. 6. The first step explains the structure of the model, the second step defines a new element, the third step defines a meta attributes, the fourth step defines meta associations. In the fifth step we constrain a new element by OCL language, and finally we create a graphical icon for the new elements.

\section{CONCLUSION AND FUTURE WORK}

UWE is a standard method but cannot fully support UTM homepage contents, because the number of elements of the 
navigation model is less than the number of models of homepages. But WebML is better than UWE because it has visual languages, and the number of the elements are more than the UWE navigation model. We have concluded that WebML is stronger than UWE in representing the navigation model. Therefore the UWE is UML profile, and WebML based on UML, so we can extend the two methods by defining the new elements for the navigation model UWE and WebML. Moreover we can further extend the UWE navigation model for solving the usability and reliability issues. We are also suggesting for the researchers to extend the navigation model through different mechanism or different techniques to enhancement of the two methods.

\section{REFERENCES}

[1] N. Koch, A. Knapp, G. Zhang, and H. Baumeister, "Uml-based web engineering," Web Engineering: Modelling and Implementing Web Applications, pp. 157-191, 2008.

[2] N. Koch and A. Kraus, "Towards a common metamodel for the development of web applications," Web Engineering, pp. 419-422, 2003.

[3] G. Booch, I. Jacobson, and J. Rumbaugh, "The unified software development process," Reading, Addison Wesley, 1999.

[4] A. Knapp, N. Koch, F. Moser, and G. Zhang, "ArgoUWE: A case tool for web applications," in Proc. 1st. International Workshop on Engineering Methods to Support Information Systems Evolution (EMSISE'03), 2003.

[5] S. Ceri, P. Fraternali, A. Bongio, M. Brambilla, S. Comai, and M. Matera, Morgan Kaufmann Series in Data Management Systems. Designing Data-Intensive Web Applications, Morgan Kaufmann Pub, 2003.

[6] M. Brambilla, S. Comai, P. Fraternali, and M. Matera, "Designing web applications with WebML and WebRatio," Web Engineering: Modelling and Implementing Web Applications, pp. 221-261, 2008.

[7] A. Burner. (2002). Comparison of web technologies and web engineering methodologies. [Online]. Available: http://www.BurnerNet. com.

[8] M. O. Leavitt and B. Shneiderman, Research-Based Web Design \& Usability Guidelines, US Department of Health and Human Services, 2006.

[9] N. Koch and A. Kraus, "Towards a common metamodel for the development of web applications," Web Engineering, Springer, 2003 pp. 497-506.

[10] K. Vlaanderen, F. Valverde, and O. Pastor, "Improvement of a web engineering method applying situational method engineering," in Proc. ICEIS (3-1), 2008, pp. 147-154.

[11] J. Conallen, Building Web Applications with UML, Addison-Wesley Professional, 2003.

[12] L. Baresi, F. Garzotto, and M. Maritati, "W2000 as a MOF Metamodel," presented at 6th World Multiconference on Systemics, Cybernetics and Informatics-Web Engineering Track, Orlando, USA, 2002.

[13] A. Kraus and N. Koch, "A metamodel for UWE," Citeseer, 2003.

[14] J. Gómez and C. Cachero, "OO-H Method: Extending UML to model web interfaces," Information Modeling for Internet Applications, pp. 144-173, 2003.

[15] A. Schauerhuber, M. Wimmer, and E. Kapsammer, "Bridging existing Web modeling languages to model-driven engineering: a metamodel for WebML," in Proc. 6th. international conference on Web engineering, 2006, p. 5.

[16] S. Meliá, J. Gómez, and N. Koch, "Improving web design methods with architecture modeling," E-Commerce and Web Technologies, Springer, 2005, pp. 53-64.

[17] C. Kroiß and N. Koch, "The UWE Metamodel and Profile--User Guide and Reference," $\quad$ Technical Report Ludwig-Maximilians-Universität München, 2011.
[18] N. Moreno, P. Fraternali, and A. Vallecillo, "WebML modelling in UML," Software, IET, vol. 1, pp. 67-80, 2007.

[19] R. Jeyakarthik, "Requirements engineering in current web engineering methodologies," International Journal, vol. 2, 2011.

[20] T. Bosch, "A web engineering approach for the development of business process-driven web applications," Ph.D. dissertation, Dept. Information Systems and Computation Technical, Univ. of Valencia, 2008.

[21] R. Gustavo, O. Pastor, D. Schwabe, and L. Olsina, "Web engineering: modelling and implementing web applications," Human-Computer Interaction Series, vol. 12, Springer, 2008.

[22] A. L. D. S. Domingues et al., "A comparison study of web development methods," 2008.

[23] T. A. Jackson, "Web page design: a study of three genres," University of North Carolina, 1999.

[24] A. Kennedy and M. Shepherd, "Automatic identification of home pages on the web," in Proc. 38th Annual Hawaii International Conference on System Sciences, 2005, p. 99c.

[25] UTM. (2013). UTM homepage. [Online]. Available: http://utm.my/

[26] Apple Inc. (2013). Apple homepage. [Online]. Available: http://www.apple.com/

[27] Maher Zain. (2013). Mherzain homepage. [Online]. Available: http://www.maherzain.com/

[28] C. Cachero and N. Koch, "Navigation analysis and navigation design in OO-H and UWE," Tehcnical Report. Universidad de Alicante, Spain, 2002.

[29] S. Casteleyn, Engineering Web Applications, Springer, 2009.

[30] U. U.-B. W. Engineering. (2012). Profile Overview. [Online]. Available: http://uwe.pst.ifi.lmu.de/profileOverview.html

[31] S. Ceri, P. Fraternali, and A. Bongio, "Web modeling language (WebML): a modeling language for designing Web sites," Computer Networks, vol. 33, pp. 137-157, 2000.

[32] P. Desfray, "UML Profiles versus Metamodel extensions: An ongoing debate," in OMG's UML Workshops: UML in the. com Enterprise: Modeling CORBA, Components, XML/XMI and Metadata Workshop, 2000, pp. 6-9.

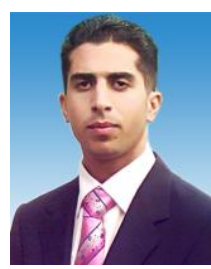

Karzan Wakil is lecturer at the Fine Arts Institute in Sulaimaniyah, Sulaimaniyah-Iraq. He received BSc. degree in computer science from Salahaddin University-Iraq-2006 and M.Sc. in computer science from University Technology Malaysia (UTM), Malaysia, 2013. His research areas are web engineering, software engineering and web systems.

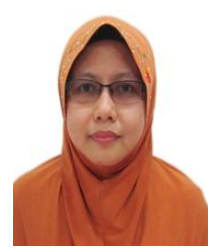

Dayang N. A Jawawi is an associate professor in Software Engineering Department, Faculty of Computing, Universiti Teknologi Malaysia (UTM). She received her B.Sc. in software engineering from Sheffield Hallam University, UK, and her M.Sc. and $\mathrm{Ph} . \mathrm{D}$. in the field of software engineering from Universiti Teknologi Malaysia. She has been an academic staff at Software Engineering Department for over ten years and she is currently serving as the head of Department since October 2009. She is a member of the Software Engineering Research Group (SERG), K-Economy Research Alliance, UTM.

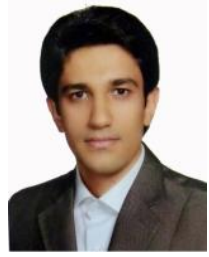

Amirhossein Safi is graduated from master of science in computer science, Universiti Teknologi Malaysia (UTM) in 2013. His bachelor degree is coming from Faculty of Computer Engineering, Shahid Bahonar University of Kerman, Iran. His current research interests include web services, service oriented architecture (SOA), distributed systems, smart environments, and web methodologies. 